\title{
Personality- and size-related metabolic performance in invasive round goby (Neogobius melanostomus)
}

Behrens, Jane; von Friesen, Lisa W.; Brodin, Tomas; Hirsch, Philipp E. ; Persson, Anders; Sundelin, Anna; van Deurs, Mikael; Nilsson, P. Anders

Published in:

Physiology \& Behavior

Link to article, DOI:

10.1016/j.physbeh.2019.112777

Publication date:

2020

Document Version

Peer reviewed version

Link back to DTU Orbit

Citation (APA):

Behrens, J., von Friesen, L. W., Brodin, T., Hirsch, P. E., Persson, A., Sundelin, A., van Deurs, M., \& Nilsson, P. A. (2020). Personality- and size-related metabolic performance in invasive round goby (Neogobius melanostomus). Physiology \& Behavior, 215, [112777]. https://doi.org/10.1016/j.physbeh.2019.112777

\section{General rights}

Copyright and moral rights for the publications made accessible in the public portal are retained by the authors and/or other copyright owners and it is a condition of accessing publications that users recognise and abide by the legal requirements associated with these rights.

- Users may download and print one copy of any publication from the public portal for the purpose of private study or research.

- You may not further distribute the material or use it for any profit-making activity or commercial gain

- You may freely distribute the URL identifying the publication in the public portal 
1 Personality- and size-related metabolic performance in invasive round goby (Neogobius

\section{melanostomus)}

Jane W. Behrens ${ }^{\mathrm{a}, *}$, Lisa W. von Friesen ${ }^{\mathrm{b}}$, Tomas Brodin ${ }^{\mathrm{c}}$, Philip Ericsson ${ }^{\mathrm{b}}$, Philipp Emanuel Hirsch ${ }^{\mathrm{d}}$, Anders Persson $^{\mathrm{b}}$, Anna Sundelin ${ }^{\mathrm{e}}$; Mikael van Deurs ${ }^{\mathrm{a}}$, P. Anders Nilsson ${ }^{\mathrm{b}, \mathrm{f}}$

${ }^{a}$ National Institute of Aquatic Resources, DTU Aqua, Technical University of Denmark, Kemitorvet, Building 202, 2800 Kgs. Lyngby, Denmark; ${ }^{b}$ Department of Biology - Aquatic Ecology, Lund

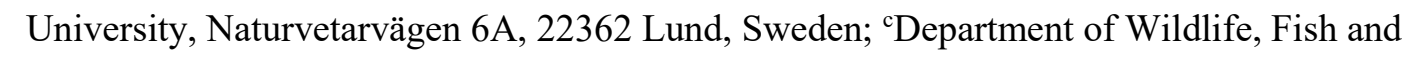
Environmental Studies, Swedish University of Agricultural Sciences (SLU) - Umeå, 90183 Umeå,

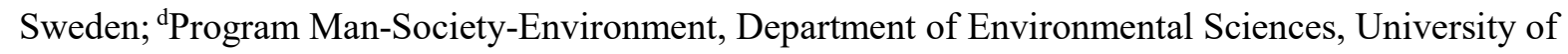
Basel, Vesalgasse 1, CH-4051 Basel, Switzerland; 'Department of Chemistry, Umeå University, Kemihuset, 90187 Umeå, Sweden; fLife Sciences, Karlstad University, 65188 Karlstad, Sweden

\section{*Corresponding author}

E-mail addresses: jabeh@aqua.dtu.dk (J. W. Behrens), lisa.vonfriesen@ivl.se (L.W.von Friesen), tomas.brodin@slu.se (T. Brodin), philip.steven.ericsson@gmail.com (P. Ericsson), philipp.hirsch@unibas.ch (P. Hirsch), anders.persson@biol.lu.se (A. Persson),

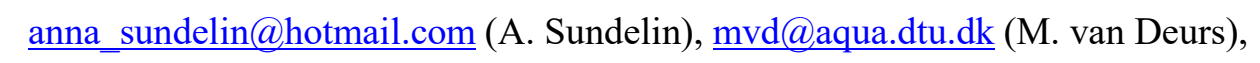
anders.nilsson@biol.lu.se (P. A Nilsson)

Declarations of interest: None

Role of financial sources in the process: None

Data behind this research article is available upon request. 


\section{Abstract}

24 Differences between individuals in behavioral type (i.e. animal personality) are ecologically and 25 evolutionarily important because they can have significant effects on fitness components such as 26 growth and predation risk. In the present study we ere used the invasive round goby (Neogobius melanostomus) from an established population in controlled experiments to examine the relationships among personality, metabolic performance, and growth rate (inferred as size-at-age). Boldness was measured as the time to return to normal behavior after a simulated predator attack, where fish with shorter freezing times were categorized as "bold" and fish with longer times were categorized as "shy". We show that bold fish have significantly higher standard metabolic rate (SMR) than their shy conspecifics, whereas there was no difference between personality types in their maximum metabolic rate (MMR) or aerobic scope (AS). Bold fish furthermore had a smaller size-at-age as compared to shy fish. Together this provides evidence of a metabolic underpinning of personality where the highSMR bold fish require more resources to sustain basic life functions than their low-SMR shy conspecifics, indicating that bold round goby from established populations with high densities (and high competition for food) pay a price of reduced growth rate.

Keywords: Behavioral syndrome; Pace-of-life syndrome; Individuality; Metabolism; Respirometry; Boldness 
The concept of animal personality (here defined as individual variation in behavioral traits, e.g. boldness, that remain constant across time and contexts) has received increasing amounts of attention over the past 15 years (Briffa and Weiss, 2010; Gosling, 2001; Réale et al., 2007). Differences between individuals in behavioral type are ecologically and evolutionarily relevant because they can have important effects on fitness or components of fitness (Sih et al., 2012; Smith and Blumstein, 2008; Wolf and Weissing, 2012). In particular, bolder, more active or aggressive animals often feed and grow at higher rates (Brown et al., 2007; Ward et al., 2004; Westerberg et al., 2004) but also take more risks and thus suffer higher mortality from predators (Biro and Stamps, 2008; Brodin and Johansson, 2004; Sih et al., 2003). In addition, a recent field study confirms that bold phenotypes do run a greater risk of predation also in the wild (Hulthén et al., 2017). Despite the attention animal personality received in connection to fitness correlates such as growth and predation risk, comparably little attention has been paid to the metabolic underpinnings of personality. Recent evidence demonstrates that being bold and having a higher tendency to disperse also comes at a metabolic cost: bolder individuals might have increased metabolic maintenance costs required for a higher performance in exploratory movements (Myles-Gonzalez et al., 2015). This suggests that the costbenefit trade-off may not only be of a 'predation susceptibility character' but also of a metabolic character. Although interest in this issue has increased, it still remains unclear whether standard metabolic rate (SMR) is a stable trait of a given individual (mass-specific SMR does not change throughout ontogeny) or whether e.g. an individual varies in SMR with size or is contingent on how fast or slow it grows. Metabolic performance in relation to individual personality is hardly ever put in context of the growth rate of the tested individuals, although the relationship between metabolism and growth rate is undisputed (see Rosenfeld et al., 2015 for a review on salmonids). Regardless of the directions of any such relationships between growth rate and SMR this relationship would potentially, at least in part, counteract the increased growth potential arising from a boldness-driven higher food access. 
Here, we use round goby (Neogobius melanostomus) as a timely model organism to examine the relationships among personality, metabolic performance and growth rate as interfered from size-atage correlations. The round goby is a very suitable species to test for metabolic costs of boldness because it is an experimentally well-understood model species for both personality (Myles-Gonzalez et al., 2015; Thorlacius et al., 2015; Thorlacius and Brodin, 2017) and metabolic measures (Behrens et al., 2017; Drouillard et al., 2018; Tierney et al., 2011) as well as the combination of both (MylesGonzalez et al., 2015). It originates from the Ponto-Caspian region but has been introduced via ship ballast water to large parts of Europe, including the Baltic Sea, and the Great Lakes in North America. It has dispersed widely in both regions and is considered one of the most impactful invasive species (Ojaveer et al., 2015; Ojaveer and Kotta, 2014). Currently, it is continuing its invasion of the Baltic Sea towards the saline North Sea (Azour et al., 2015; Behrens et al., 2017). Recent studies have documented personality-dependent dispersal in this species (Thorlacius et al., 2015; Thorlacius and Brodin, 2017), and it has been argued that 'bigger is better' for fish leading the invasion front, i.e. individuals found at the border of a range expansion have a larger body size than individuals at the center (Brandner et al., 2013). Using fish from an established population in the western Baltic, we here i) performed personality assays on round goby, ii) tested whether individuals of different behavioral types differ in their overall aerobic metabolic performance, and iii) compared the size distribution (length and weight) of the bold versus shy round gobies.

\section{Material and Methods}

\subsection{Fish and holding facilities}

Round goby (approximately 400 fish) were caught April 2017 with fyke nets in the brackish water estuary Guldborgsund (salinity 10 PSU (Olsen, 2002)) in the western Baltic Sea $\left(54^{\circ} 42^{\prime} \mathrm{N}, 11^{\circ} 51^{\prime} \mathrm{E}\right)$. The gender of individual fish was determined on location by examination of the urogenital papilla (Marsden et al., 1996) and only males (approx. 200 in total) were collected to exclude any potential gender-mediated differences. The fish were transported to DTU Aqua, Lyngby, Denmark, and held in 
five 15001 tanks with $10 \pm 1{ }^{\circ} \mathrm{C}$, recirculated and aerated $10 \pm 0.5$ PSU water. All tanks were enriched with fine-grain gravel on the bottom as well as artificial seagrass and PVC tubes (diameter $7.5 \mathrm{~cm}$ ) to provide shelter. The light:dark cycle followed the natural cycle, changing from 16:8 to 14:10 during the course of the study. Following one week of acclimation to the holding conditions, individual fish were tagged with passive integrated transponder tags (PIT tags; $12 \times 2 \mathrm{~mm} ; 0.1 \mathrm{~g}$; Oregon RFID) into the body cavity using disposable 12.2-gauge syringe implanters, and fish weights and lengths were noted. Fish were observed twice daily after tagging and fed to satiation with defrosted shrimp every third day (the feeding schedule was however adjusted according to experimental protocols, see details below). Ethical permit 2017-15-0201-01282 from the Danish Animal Ethics Committee covered all experiments reported here.

\subsection{Boldness assays}

Boldness assays were started 10 days after tagging. The fish were kept on a feeding schedule such that they were fed two days before starting the trial. Approximately 25 fish went through the boldness trial per day, and a total of 182 fish participated in assays. A non-transparent wall (brown cardboard paper) was placed in front of each experimental aquarium to reduce disturbance from the surroundings. The aquaria were rotated $180^{\circ}$ each day to eliminate orientation effects, and the water was exchanged twice daily (midday and at the end of each experimental day) with water from the holding tanks, and faeces were removed between each individual. Each individual fish was placed in the middle of an experimental aquarium $(30 \times 35 \times 60 \mathrm{~cm}$, water depth $15 \mathrm{~cm})$ and left to acclimate for five minutes. Thereafter, a bolt attached to a fishing line was released into the middle of the aquarium, penetrating the water surface with a depth of $5 \mathrm{~cm}$ and a distance of $0-2$ body lengths from the fish to simulate a bird attack. The bolt was retracted after one second, and the whole procedure was recorded on video

118 from above for 30 minutes (SONY, Handycam, HDR-CX405). Directly after each trial, the fish were

119 moved back to the holding tanks. Boldness was defined and analyzed according to Thorlacius et al.

120 (2015). In short, boldness was measured as an individual's ability to return to normal behavior after a stressful situation, such as a predator encounter. More specifically, this was done by exposing the fish 
freezing (i.e. freezing time). Shorter time indicates higher level of boldness, i.e. higher ability to return to normal behavior after a predator attack. Freezing time were used to indicate levels of boldness for individual round goby, as it has been commonly used to measure boldness and has been proven repeatable in this species (Thorlacius et al., 2015). The recordings were analyzed with the software ToxTrac ver. 2.80 (Rodriguez et al., 2018). To determine the consistency of boldness, the boldness trial was repeated for 62 fish ( 26 bold, 26 shy and 10 intermediate).

\subsection{Metabolism}

To determine fish aerobic metabolic performance, the individuals' standard metabolic rates (SMR; the oxygen uptake of a resting, fasting fish) and maximum metabolic rate (MMR; the maximum oxygen uptake following exhaustive exercise) were measured. SMR represents the energetic cost of self maintenance (Chabot et al., 2016), where individuals with high SMR require more resources to sustain basic life functions than individuals with low SMR (Auer et al., 2018). MMR on the other hand, sets the ceiling for fish capacity to metabolize oxygen, and has been shown to vary across animal lifestyles (Behrens et al., 2006; Norin and Clark, 2016). The difference between SMR and MMR, the aerobic scope (AS), is the metabolic range within which all aerobic activities must take place; the AS is thus considered to be linked to the performance and fitness of the individual (Behrens et al., 2018; Fry, 1947; Norin and Clark, 2016).

140 Nineteen fish (9 bold of mean weight $41 \pm 7 \mathrm{~g}(\mathrm{SD})$ and 10 shy of mean weight $44 \pm 6 \mathrm{~g}(\mathrm{SD})$ ) were used in respirometry trials. Originally 10 fish of each personality type were chosen, but one trial with a bold fish had computer failure and no data was collected. The fish were chosen randomly amongst the total 26 bold and 26 shy fish, respectively, however still (by visual inspection) aiming to sizematch the two groups, to minimize the risk of a size effect on metabolic rate. Individuals were fasted for three to five days before being placed in the respirometer. Two respirometers with volumes of 1126 and $1157 \mathrm{ml}$ were held in a 6001 tank, with $10 \pm 1{ }^{\circ} \mathrm{C}$, recirculated and aerated $10 \pm 0.5 \mathrm{PSU}$ water. To minimize visual disturbance, the respirometers were shielded off from each other and from above with opaque polyethylene plates. Oxygen consumption rate $\left(\mathrm{MO}_{2}\right)$ was measured with an 
measured every second with fiber-optic sensors, connected to a Witrox 4 oxymeter (Loligo Systems,

151 Tjele, Denmark). Using the software AutoResp ${ }^{\mathrm{TM}}$ (Loligo Systems, Tjele, Denmark) $\frac{d p O 2}{d t}\left(\mathrm{kPaO}_{2} \mathrm{~h}^{-1}\right)$ was determined by linear regression and $\mathrm{MO}_{2}\left(\mathrm{mg} \mathrm{O}_{2} \mathrm{~kg}^{-1} \mathrm{~h}^{-1}\right)$ calculated according to the equation:

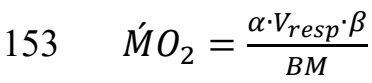

154 where $\alpha$ is the $\frac{d p O 2}{d t}, \mathrm{~V}_{\text {resp }}$ is the total volume of the respirometer minus the volume of the fish (L), $\beta$ is oxygen solubility at the given temperature and salinity and BM is the body mass of the fish $(\mathrm{kg})$. The animal volume was calculated from its mass, assuming neutral density in water.

All respirometry trials began between 1 and $2 \mathrm{pm}$. To yield maximum metabolic rate (MMR), individual fish underwent an exhaustive chase and air exposure protocol ( $3 \mathrm{~min} 30 \mathrm{sec}$ in total) (Norin and Clark, 2016). More specifically, individual fish were placed in a circular tank $(60 \mathrm{~cm}$ diameter, water depth $15 \mathrm{~cm}$ ) with aerated water of the same temperature and salinity as the respirometer. Each fish was chased continuously by hand for $1 \mathrm{~min}$ and then netted and exposed to air for 10seconds (s). This procedure was repeated three times, after which the fish was placed in the respirometer. The first $\dot{\mathrm{MO}} 2$ measurement was taken with a wait period of $60 \mathrm{~s}$ and a measuring period of $150 \mathrm{~s}$ (Behrens et al., 2017). For all fish, this $\dot{\mathrm{MO}}_{2}$ value after the chase protocol was always the highest reported during the trial and thus taken as MMR. After measurement of MMR, fish remained in the respirometers overnight to allow for $\mathrm{MO}_{2}$ measurement of the individual at a resting, non-digesting state (standard metabolic rate; SMR (Chabot et al., 2016). For SMR 10min loops were used, with a flush period of $240 \mathrm{~s}$, a wait period of $60 \mathrm{~s}$, and a measuring period of $300 \mathrm{~s}$. A single experimental trial lasted approximately $24 \mathrm{~h}$ and SMR was estimated as the average of the $10 \%$ lowest $\mathrm{MO}_{2}$ measurements during this period. Background (bacterial) $\dot{\mathrm{MO}}_{2}$ was subsequently determined in the chamber without fish and the value subtracted. On average, background $\dot{\mathrm{MO}}_{2}$ levels were $2 \%$ of SMR. Every day, subsequent to a trial, the respirometers, including tubing, were dissembled and cleaned in warm fresh water and soap. 
Spearman's rank correlation was used to estimate the consistency of individual boldness scores between the two personality assay periods, and the repeatability of boldness score measurements were estimated using intraclass correlation coefficient (ICC). Statistical tests were carried out using SPSS Statistics (version 24)

\subsubsection{Metabolism}

The three dependent variables SMR, MMR and AS were compared between goby personalities (bold vs shy) in a MANCOVA with goby individual wet weights as covariate $(\mathrm{y} \sim$ personality + wet weight + personality $\times$ wet weight). Statistical tests were carried out using SPSS Statistics (version 25).

\subsubsection{Weight and length analysis}

In order to test if personality was related to size, mean weight, and length, the whole 'lab population' of shy and bold fish were compared using a t-test. Differences in the mean weight of shy and bold fish could be due to either growth effects or age effects. We therefore used the length-age relationship from Azour et al. (2015) to inform us about the possible ages of fish within specified length intervals (fish from Azour et al. (2015) were caught in the same place as fish used in the present study). According to Azour et al. (2015) fish between 12 and $14.5 \mathrm{~cm}$ are highly likely to be 2 years old (i.e. there was no overlap with younger and older fish within this length interval). Hence, the t-test comparison of mean weight for shy and bold fish was repeated, but this time only using fish from within this length interval. If a significant difference in weight between bold and shy fish persisted within this length interval as well, any size effect on personality would likely be the result of an underlying relationship between growth rate and personality (opposed to a relationship between age and personality). If not, the weight difference would more likely be the result of an age-effect. Statistical tests were carried out using R with Rstudio (version 3.6.0). 


\subsection{Personality}

202

Boldness of round goby was both consistent and repeatable over the one-month period between the trials (consistency: Spearman's rho $=0.48, \mathrm{p}<0.001$; repeatability: $\mathrm{F}_{61,62}=2.68, \mathrm{p}<0.001, \mathrm{ICC}=$ $0.457,95 \% \mathrm{CI}=0.269-0.655)$.

The full, initial MANCOVA model was reduced by removing the non-significant personality $\times$ wet weight interaction term (Wilks' $\lambda=0.932, \mathrm{~F}_{2,14}=0.509, \mathrm{p}=0.612$ ). The resulting, reduced model was further reduced by removing the non-significant covariate wet weight (Wilks' $\lambda=0.990, \mathrm{~F}_{2,15}=0.075$, $\mathrm{p}=0.928$ ). The resulting MANOVA model indicated a significant effect of personality (Wilks' $\lambda$

$210=0.650, \mathrm{~F}_{2,16}=4.302, \mathrm{p}=0.032$, partial $\eta^{2}=0.350$ ). A univariate between-subject effects test showed that this effect was due to an effect of personality on $\operatorname{SMR}\left(\mathrm{F}_{1,17}=7.476, \mathrm{p}=0.014\right.$, partial $\left.\eta^{2}=0.305\right)$, but neither on $\operatorname{MMR}\left(\mathrm{F}_{1,17}=0.065, \mathrm{p}=0.801\right.$, partial $\left.\eta^{2}=0.004\right)$ nor $\mathrm{AS}\left(\mathrm{F}_{1,17}=0.020, \mathrm{p}=0.890\right.$, partial

$\left.213 \eta^{2}=0.001\right)$. Variances did not differ between groups (Levene statistic $\leq 0.041, p \geq 0.842$ ) and residuals 214 did not deviate from normality (Shapiro-Wilk $\geq 0.922, \mathrm{p} \geq 0.124)$. The mean ( $\pm \mathrm{SD}$ ) SMR, MMR and

215 AS of the bold and shy fish were $41 \pm 2$ and $27 \pm 2 \mathrm{mg} \mathrm{O}_{2} \mathrm{~kg}^{-1} \mathrm{~h}^{-1}, 300 \pm 13$ and $238 \pm 14 \mathrm{mg} \mathrm{O}_{2} \mathrm{~kg}^{-1}$

$216 \mathrm{~h}^{-1}$, and $259 \pm 12$ and $211 \pm 13 \mathrm{mg} \mathrm{O}_{2} \mathrm{~kg}^{-1} \mathrm{~h}^{-1}$, respectively (Figure 1). 
217 Single column fitting image - Figure 1:
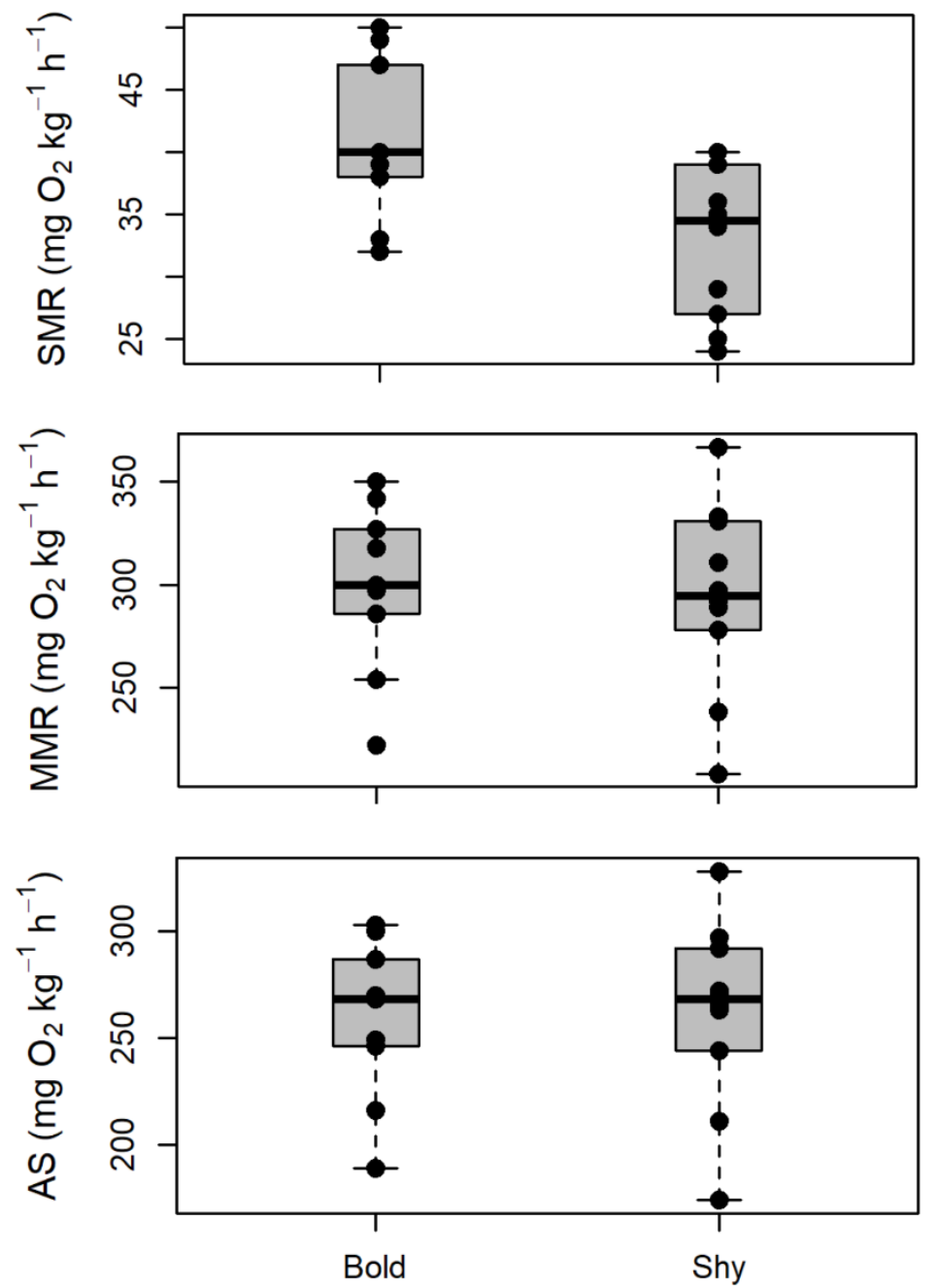
Figure 1. Standard metabolic rate (SMR), maximum metabolic rate (MMR) and aerobic scope (AS; MMR - SMR) for bold ( $\mathrm{n}=9)$ and shy $(\mathrm{n}=10)$ round goby. Bars represent first, second (i.e. median), and third quartiles, while whiskers represent $95 \%$ confidence intervals. Individual data points are indicated with circles.

Bold fish weighed significantly less than shy fish $(40.6 \pm 14.8 \mathrm{~g}$ and $48.9 \pm 13.8 \mathrm{~g}$, respectively) $\left(\mathrm{t}_{60.1}=2.55, \mathrm{p}=0.014\right)$ and were significantly shorter $(13.9 \pm 1.5 \mathrm{~cm}$ and $14.8 \pm 1.1 \mathrm{~cm}$, respectively $)$ $\left(\mathrm{t}_{57.8}=2.67, \mathrm{p}=0.010\right)$. Out of the original 65 fish (33 bold fish and 32 shy fish), 31 fish (19 bold and 12 shy fish) belonged to the length interval from 12 to $14.5 \mathrm{~cm}$ (i.e. being 2 years of age). The size difference between bold and shy fish within this selected group of 2 year old fish (weight: $30.9 \pm 6 . \mathrm{g}$ and $37.9 \pm 4.6 \mathrm{~g}$ respectively, length: $12.9 \pm 0.8 \mathrm{~cm}$ and $13.7 \pm 0.4 \mathrm{~cm}$, respectively) was also significant (weight comparison: $\mathrm{t}_{28.3}=3.58, \mathrm{p}=0.001$; length comparison: $\mathrm{t}_{28.2}=3.73, \mathrm{p}<0.001$ ), inferring a relationship between growth rate and personality, rather than between age and personality (Figure 2). 


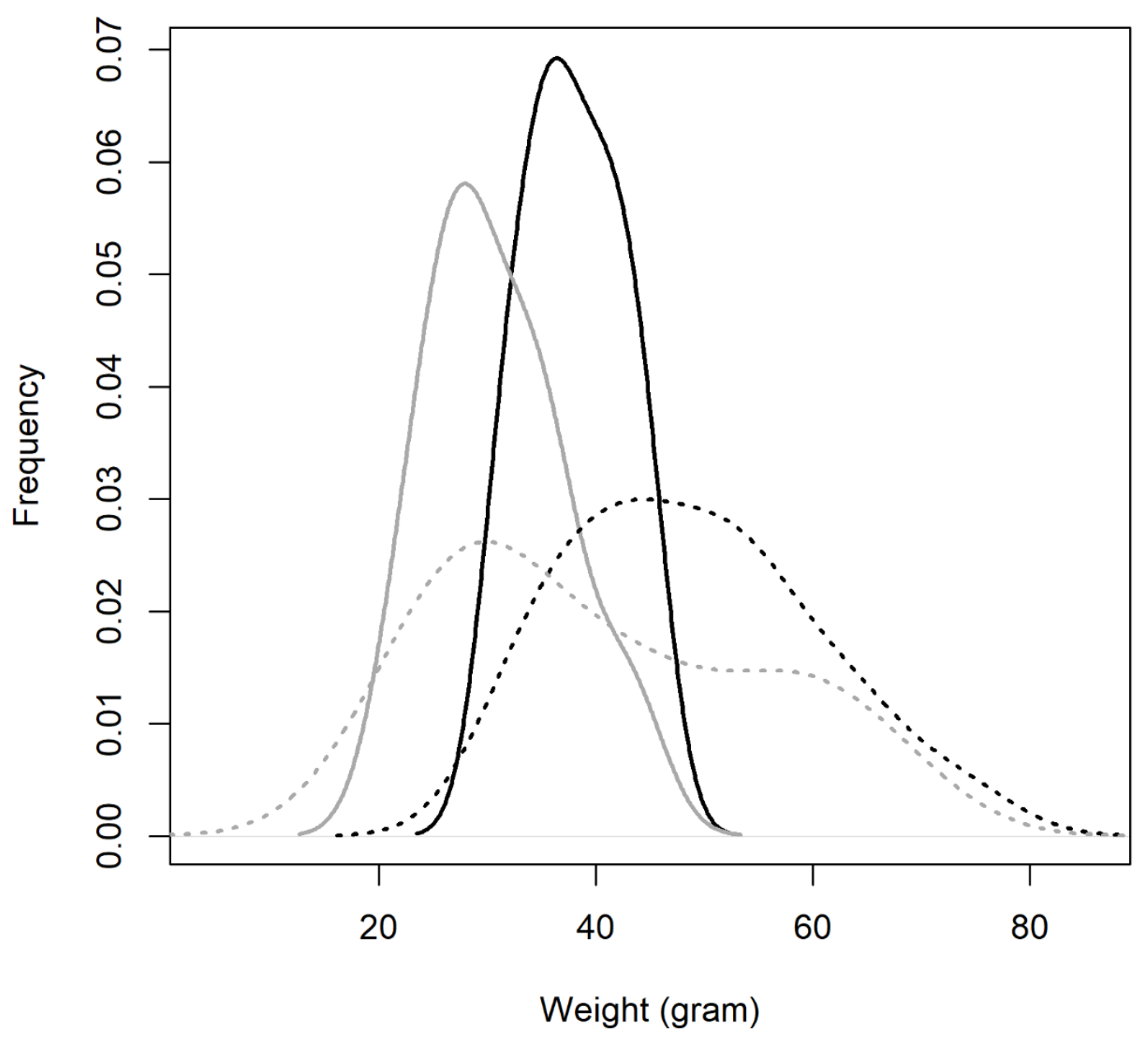

246 Figure 2. Weight frequency distributions of bold (grey) and shy (black) round goby, respectively.

247 Dashed lines represent all fish and solid lines represents only the fish from the size interval that 248 according to Azour et al. (2015) is comprised exclusively of 2-year-old fish. 
In this study, we tested whether metabolism (SMR, MMR and AS) is related to boldness and found that bolder individuals have higher SMR. When comparing the metabolic performance to the size of the fish, we found that bolder fish were significantly smaller than their shy conspecifics of the same age. Taken together, this suggests a metabolic underpinning of personality, and that bold round goby pay the price of a reduced growth rate.

4.1 Differences in metabolic rate between personality types - hints towards a behavior-physiology syndrome?

Our results reveal pronounced inter-individual variation in metabolic parameters (SMR, MMR and AS). On average all parameters were elevated in bold individuals relative to shy individuals, yet only SMR turned out to be significantly different. In general, the observation that bolder fish have a higher SMR matches well with previous work. For example, Auer et al. (2018) showed that replicated populations of the Trinidadian guppy (Poecilia reticulata) that evolved a fast-paced life history also had consistently higher SMR than guppies that evolved a slow-paced life history. The same pattern of higher SMR in bold fish was found in a recent experimental study on the olive flounder, Paralichthys olivaceus (Rupia et al., 2016). Despite increasing scientific interest, the correlations between metabolic rate, pace of life and phenotypic traits are less than clear (Careau et al., 2009; Harvey et al., 1991; Lovegrove, 2009; White and Seymour, 2004). Our study adds to the growing evidence for a positive correlation between metabolic rate and a phenotypic trait: Standard metabolic rate (SMR) and boldness.

Intriguingly, and in contrast to SMR, neither MMR nor AS were significantly elevated in bold gobies. MMR and AS are both measures linked to the performance of the individual: MMR sets the ceiling for aerobic metabolic performance, and AS constitutes the metabolic confinement within which aerobic activities must take place (Behrens et al., 2018, 2006; Fry, 1947; Norin and Clark, 2016). This discrepancy may seem surprising, because a higher SMR unmatched with a higher aerobic metabolic capacity is more of a fitness burden than a fitness advantage. In other species, boldness has been 
shown to be accompanied by higher aerobic metabolic capacity, e.g. bold bluegill sunfish, Lepomis macrochirus, having $25 \%$ greater AS compared to shy fish, supported by a $15 \%$ greater MMR (Binder et al., 2016), and bold olive flounder likewise exhibited both increased MMR and AS (Rupia et al., 2016). Notably, high and low MMR are generally believed to correlate with more athletic and sedentary lifestyles, respectively (Norin and Clark, 2016). Round goby is a sedentary benthic fish that rarely undertakes prolonged swimming and rather displays a burst-and-hold swim style (Tierney et al., 2011; Kornis et al., 2012). So it could be speculated that in the absence of movements requiring aerobic endurance, there may simply be no evolutionary benefits of high MMR (or AS) in this species, irrespectively of personality. Short sprint-type swims (including also escapes from predators) might have a different metabolic underpinning, relying fully or partly on anaerobic energy production, where the strength and/or duration of the response could differ among behavioural types (Killen et al., 2013). To strengthen our mechanistic understanding of the physiological ramifications of behavioral types it would thus be of interest to investigate potential causal links between personality and capacity for anaerobic energy production.

Overall, if we were to formulate a behavior-physiology syndrome based on our results bolder round goby should be more inclined towards exploratory behavior, increasing prey encounter rates - but also predator encounter rates. For smaller size-at-age round goby this poses a particular risk since a smaller body size in fish typically translates into higher predation risk compared to a larger body size (Ebenman and Persson, 1988; Hambright, 1991; Nilsson and Bronmark, 2000).

\subsection{Ecological implications of growth-rate specific personality and SMR differences}

Growth rate in fish can be a highly heritable trait. While there is no information on how plastic the growth rate is in round goby, it should be safe to assume that our indirect measure of size-at-age is a robust estimator of growth rate at the time of measurement of SMR. The difference in size-at-age in concert with the SMR difference between shy and bold individuals suggests a connection between growth rate, SMR and personality. Based on this connection we speculate that bolder and smaller individuals are simply forced to take risks such as predation encounters because of their higher SMR relative to larger and shyer conspecifics. In other words, the high-SMR bold fish require more 
resources to sustain basic life functions than their low-SMR shy conspecifics, and, at least in some species, bold phenotypes do run a greater risk of predation in the wild (Hulthén et al., 2017). Alternatively, assuming that food intake is equal, less energy can be allocated for somatic growth in bold fish. Future studies focusing on a more controlled manipulation of e.g. food intake and thus growth and size across different individuals are needed. Such manipulative studies should convey indicated mechanisms behind the relationship between growth rate and SMR.

\subsection{Consideration on invasion history in relation to size of bold round goby}

312 Round goby in the present study originated from an established (since 2009), high-density population, where the fish (suggestively due to high competition for food) are overall slower-growing and in poorer condition compared to fish sampled from recently invaded locations further northward along the coastline (Azour et al., 2015). In the Danube river system, round goby from founder populations at the invasion front differed in a variety of traits compared to longer-established round goby populations, including being larger and heavier, and with higher condition factors than those from established areas, their larger size resulting in superior competitive ability for food (Brandner et al., 2013). In these two studies, fish were not examined for personality type, but recent studies have documented personality-dependent dispersal in this species, with bold, asocial round goby being more prone to lead the invasion front (Thorlacius et al., 2015; Thorlacius and Brodin, 2017). In addition, behavioral differentiation between young and old populations has been documented in the Baltic Sea, suggesting phenotype-dependent dispersal or environmental filtering of phenotypes (Thorlacius et al. in review). Recent research also found that round goby from an invasion front had higher SMR than individuals from established areas (Myles-Gonzalez et al., 2015).

From the present study we can conclude that being bold not only entails an increased metabolic cost (higher SMR), but that this relationship is also reflected in a smaller size-at-age in a well-established population. This provides some first empirical insights into novel connections of fish individuality to a classic ecological prediction for invasive species: that increasing interspecific density and competition for food will eventually limit growth rates in newly established populations (Strayer et al., 2017). Indeed, this prediction has been experimentally confirmed in round goby, which starkly 
332 decrease growth rates with increasing population density due to interference competition (Kornis et 333 al., 2014).

4.4 Future research on relevant connections between personality, metabolism, and growth rate

336 Based on our data it would be of great interest to further investigate if bold round goby from the

337 invasion front further north along the coastline are larger, and if that reflects an ability to offset the

338 increased energetic demand (i.e. higher SMR) by superior access to, and decreased competition for,

339 food. Such knowledge could play a crucial role in explaining the dynamics in population density that

340 many invasive populations go through (Strayer et al. (2017), but could also be important for better

341 predicting the ecological consequences of a biological invasion. Furthermore, since round goby

342 largely rely on anaerobically fueled burst-type swimming, determinations of lactate levels after a

343 chase protocol could reveal if the capacity for anaerobic energy production vary among behavioural

344 types.

346 Acknowledgements

347 Funding

348 This work resulted from funding from The Gyllenstiernska Krapperup's Foundation and the BONUS

349 INSPIRE project supported by BONUS (Art 185), funded jointly by the EU and the Swedish

350 Research Council Formas.

References

Auer, S.K., Dick, C.A., Metcalfe, N.B., Reznick, D.N., 2018. Metabolic rate evolves rapidly and in parallel with the pace of life history. Nat. Commun. 9, 14. https://doi.org/10.1038/s41467-017$02514-\mathrm{z}$ 
Azour, F., van Deurs, M., Behrens, J., Carl, H., Hüssy, K., Greisen, K., Ebert, R., Møller, P.R., 2015. Invasion rate and population characteristics of the round goby Neogobius melanostomus: Effects of density and invasion history. Aquat. Biol. 24, 41-52. https://doi.org/10.3354/ab00634

Behrens, J., Svendsen, J., Neuenfeldt, S., Andersen, N., van Deurs, M., 2018. Individual variation in aerobic scope affects modeled vertical foraging migration in Atlantic cod Gadus morhua, but only in moderate hypoxia. Mar. Ecol. Prog. Ser. 599, 201-208. https://doi.org/10.3354/meps12629

Behrens, J.W., Deurs, M. Van, Christensen, E.A.F., 2017. Evaluating dispersal potential of an invasive fish by the use of aerobic scope and osmoregulation capacity 1-19. https://doi.org/10.1371/journal.pone.0176038

Behrens, J.W., Præbel, K., Steffensen, J.F., 2006. Swimming energetics of the Barents Sea capelin (Mallotus villosus) during the spawning migration period. J. Exp. Mar. Bio. Ecol. 331, 208-216. https://doi.org/10.1016/j.jembe.2005.10.012

Binder, T.R., Wilson, A.D.M., Wilson, S.M., Suski, C.D., Godin, J.-G.J., Cooke, S.J., 2016. Is there a pace-of-life syndrome linking boldness and metabolic capacity for locomotion in bluegill sunfish? Anim. Behav. 121, 175-183. https://doi.org/10.1016/j.anbehav.2016.09.006

Biro, P.A., Stamps, J.A., 2008. Are animal personality traits linked to life-history productivity? Trends Ecol. Evol. 23, 361-368. https://doi.org/10.1016/j.tree.2008.04.003

Brandner, J., Cerwenka, A.F., Schliewen, U.K., Geist, J., 2013. Bigger Is Better: Characteristics of Round Gobies Forming an Invasion Front in the Danube River. PLoS One 8, e73036. https://doi.org/10.1371/journal.pone.0073036

Briffa, M., Weiss, A., 2010. Animal personality. Curr. Biol. 20, R912-R914. https://doi.org/10.1016/j.cub.2010.09.019

Brodin, T., Johansson, F., 2004. CONFLICTING SELECTION PRESSURES ON THE GROWTH/PREDATION-RISK TRADE-OFF IN A DAMSELFLY. Ecology 85, 2927-2932. https://doi.org/10.1890/03-3120 
Brown, C., Burgess, F., Braithwaite, V.A., 2007. Heritable and experiential effects on boldness in a tropical poeciliid. Behav. Ecol. Sociobiol. 62, 237-243. https://doi.org/10.1007/s00265-007$0458-3$

Careau, V., Bininda-Emonds, O.R.P., Thomas, D.W., Réale, D., Humphries, M.M., 2009. Exploration strategies map along fast-slow metabolic and life-history continua in muroid rodents. Funct. Ecol. 23, 150-156. https://doi.org/10.1111/j.1365-2435.2008.01468.x

Chabot, D., Steffensen, J.F., Farrell, A.P., 2016. The determination of standard metabolic rate in fishes. J. Fish Biol. 88, 81-121. https://doi.org/10.1111/jfb.12845

Drouillard, K.G., Feary, D.A., Sun, X., O’Neil, J.A., Leadley, T., Johnson, T.B., 2018. Comparison of thermal tolerance and standard metabolic rate of two Great Lakes invasive fish species. J. Great Lakes Res. 44, 476-481. https://doi.org/https://doi.org/10.1016/j.jglr.2018.02.010

Ebenman, B., Persson, L., 1988. Introduction Dynamics of Size-Structured Populations: An Overview, in: Size-Structured Populations. Springer Berlin Heidelberg, Berlin, Heidelberg, pp. 3-9. https://doi.org/10.1007/978-3-642-74001-5_2

Fry, F.E.J., 1947. Effect of the Environment on Animal Activity. Stud. Biol. Ser. 55.

Gosling, S.D., 2001. From mice to men: What can we learn about personality from animal research? Psychol. Bull. 127, 45-86. https://doi.org/10.1037/0033-2909.127.1.45

Hambright, K.D., 1991. Gape-limited piscivores, planktivore size refuges, and the trophic cascade hypothesis. Arch Hydrobiol 121, 389-404.

Harvey, P.H., Pagel, M.D., Rees, J.A., 1991. Mammalian Metabolism and Life Histories. Am. Nat. 137, 556-566. https://doi.org/10.1086/285183

Hulthén, K., Chapman, B.B., Nilsson, P.A., Hansson, L.-A., Skov, C., Brodersen, J., Vinterstare, J., Brönmark, C., 2017. A predation cost to bold fish in the wild. Sci. Rep. 7, 1239. https://doi.org/10.1038/s41598-017-01270-w

Killen, S.S., Marras, S., Metcalfe, N.B., McKenzie, D.J., Domenici, P., 2013. Environmental stressors 

alter relationships between physiology and behaviour. Trends Ecol. Evol. 28, 651-658. https://doi.org/10.1016/j.tree.2013.05.005

Kornis, M.S., Carlson, J., Lehrer-Brey, G., Vander Zanden, M.J., 2014. Experimental evidence that ecological effects of an invasive fish are reduced at high densities. Oecologia 175, 325-334. https://doi.org/10.1007/s00442-014-2899-5

Kornis, M.S., Mercado-Silva, N., vander Zanden, M.J., 2012. Twenty years of invasion: A review of round goby Neogobius melanostomus biology, spread and ecological implications. J. Fish Biol. 80, 235-285. https://doi.org/10.1111/j.1095-8649.2011.03157.x

Lovegrove, B.G., 2009. Age at first reproduction and growth rate are independent of basal metabolic rate in mammals. J. Comp. Physiol. B 179, 391-401. https://doi.org/10.1007/s00360-008-0322-4

Marsden, J.E., Charlebois, P., Wolfe, K., Jude, D.J., Rudnicka, S., 1996. The round goby (Neogobius melanostomus): a review of European and North American literature. INHS Center for Aquatic Ecology.

Myles-Gonzalez, E., Burness, G., Yavno, S., Rooke, A., Fox, M.G., 2015. To boldly go where no goby has gone before: Boldness, dispersal tendency, and metabolism at the invasion front. Behav. Ecol. 26, 1083-1090. https://doi.org/10.1093/beheco/arv050

Nilsson, P.A., Bronmark, C., 2000. Prey vulnerability to a gape-size limited predator: behavioural and morphological impacts on northern pike piscivory. Oikos 88, 539-546. https://doi.org/10.1034/j.1600-0706.2000.880310.x

Norin, T., Clark, T.D., 2016. Measurement and relevance of maximum metabolic rate in fishes. J. Fish Biol. 88, 122-151. https://doi.org/10.1111/jfb.12796

Ojaveer, H., Galil, B., Lehtiniemi, M., Christoffersen, M., Clink, S., Florin, A.-B., Gruszka, P., Puntila, R., Behrens, J., 2015. Twenty five years of invasion: management of the round goby Neogobius melanostomus in the Baltic Sea. Manag. Biol. Invasions 6, 329-339. https://doi.org/10.3391/mbi.2015.6.4.02 
Ojaveer, H., Kotta, J., 2014. Ecosystem impacts of the widespread non-indigenous species in the Baltic Sea: literature survey evidences major limitations in knowledge. Hydrobiologia 750, 171185. https://doi.org/10.1007/s10750-014-2080-5

Olsen, J.S., 2002. Vækst, migration og reproduktion hos en dansk population af brakvandsaborre (Perca fluviatilis L.).

Réale, D., Reader, S.M., Sol, D., McDougall, P.T., Dingemanse, N.J., 2007. Integrating animal temperament within ecology and evolution. Biol. Rev. 82, 291-318. https://doi.org/10.1111/j.1469-185X.2007.00010.x

Rodriguez, A., Zhang, H., Klaminder, J., Brodin, T., Andersson, P.L., Andersson, M., 2018. ToxTrac : A fast and robust software for tracking organisms. Methods Ecol. Evol. 9, 460-464. https://doi.org/10.1111/2041-210X.12874

Rosenfeld, J., Van Leeuwen, T., Richards, J., Allen, D., 2015. Relationship between growth and standard metabolic rate: measurement artefacts and implications for habitat use and life-history adaptation in salmonids. J. Anim. Ecol. 84, 4-20. https://doi.org/10.1111/1365-2656.12260

Rupia, E.J., Binning, S.A., Roche, D.G., Lu, W., 2016. Fight-flight or freeze-hide? Personality and metabolic phenotype mediate physiological defence responses in flatfish. J. Anim. Ecol. 85, 927-937. https://doi.org/10.1111/1365-2656.12524

Sih, A., Cote, J., Evans, M., Fogarty, S., Pruitt, J., 2012. Ecological implications of behavioural syndromes. Ecol. Lett. 15, 278-289. https://doi.org/10.1111/j.1461-0248.2011.01731.x

Sih, A., Kats, L.B., Maurer, E.F., 2003. Behavioural correlations across situations and the evolution of antipredator behaviour in a sunfish-salamander system. Anim. Behav. 65, 29-44. https://doi.org/10.1006/anbe.2002.2025

Smith, B.R., Blumstein, D.T., 2008. Fitness consequences of personality: a meta-analysis. Behav. Ecol. 19, 448-455. https://doi.org/10.1093/beheco/arm144

Strayer, D.L., D’Antonio, C.M., Essl, F., Fowler, M.S., Geist, J., Hilt, S., Jarić, I., Jöhnk, K., Jones, 
C.G., Lambin, X., Latzka, A.W., Pergl, J., Pyšek, P., Robertson, P., von Schmalensee, M., Stefansson, R.A., Wright, J., Jeschke, J.M., 2017. Boom-bust dynamics in biological invasions: towards an improved application of the concept. Ecol. Lett. 20, 1337-1350. https://doi.org/10.1111/ele.12822

Thorlacius, M., Brodin, T., 2017. Investigating large-scale invasion patterns using-small scale invasion successions-phenotypic differentiation of the invasive round goby ( Neogobius melanostomus ) at invasion fronts. Limnol. Oceanogr. 63, 702-713. https://doi.org/10.1002/lno.10661

Thorlacius, M., Hellström, G., Brodin, T., 2015. Behavioral dependent dispersal in the invasive round goby Neogobius melanostomus depends on population age. Curr. Zool. 61, 529-542. https://doi.org/10.1093/czoolo/61.3.529

Tierney, K.B., Kasurak, A. V, Zielinski, B.S., Higgs, D.M., 2011. Swimming performance and invasion potential of the round goby. Environ. Biol. Fishes 92, 491-502. https://doi.org/10.1007/s10641-011-9867-2

Ward, A.J.W., Thomas, P., Hart, P.J.B., Krause, J., 2004. Correlates of boldness in three-spined sticklebacks (Gasterosteus aculeatus). Behav. Ecol. Sociobiol. 55, 561-568. https://doi.org/10.1007/s00265-003-0751-8

Westerberg, M., Staffan, F., Magnhagen, C., 2004. Influence of predation risk on individual competitive ability and growth in Eurasian perch, Perca fluviatilis. Anim. Behav. 67, 273-279. https://doi.org/10.1016/j.anbehav.2003.06.003

White, C.R., Seymour, R.S., 2004. Does Basal Metabolic Rate Contain a Useful Signal? Mammalian BMR Allometry and Correlations with a Selection of Physiological, Ecological, and LifeHistory Variables. Physiol. Biochem. Zool. 77, 929-941. https://doi.org/10.1086/425186

Wolf, M., Weissing, F.J., 2012. Animal personalities: consequences for ecology and evolution. Trends Ecol. Evol. 27, 452-461. https://doi.org/10.1016/j.tree.2012.05.001 